\title{
THE EFFECT OF IMPURITIES ON THE PROPERTIES OF STEEL WIRE
}

\author{
Kateřina KREISLOVA, Libor TUREK
}

sVUOM Ltd., Prague, Czech Republic, EU, kreislova@svuom.cz

https://doi.org/10.37904/metal.2019.866

\section{Abstract}

The steel wires are used as strand core for phase conductors in electrical distribution network. The mechanical properties of these wires are tested by tensile strength, twist and winding tests before production of conductors. The new wires failed in winding test. The analysis of failure reasons was performed. The results show the negative effects of various impurities in steel.

Keywords: Steel wire, mechanical properties, testing, impurities, chemical composition

\section{INTRODUCTION}

Fracture is the most common failure mode of wires. Depending on the ability of material to undergo plastic deformation before the fracture two fracture modes can be defined:

- ductile - high energy is absorbed by microvoid coalescence during ductile failure (high energy fracture mode),

- $\quad$ brittle - low energy is absorbed during transgranular cleavage fracture (low energy fracture mode).

The long-term exposed phase conductors, more than 50 years, sometimes failed due to fracture of all stands include the galvanized steel core wires. The mode of fracture is documented on Figure 1 and shows ductile mode with plastic deformation due to long-term combined corrosion and mechanical stress.
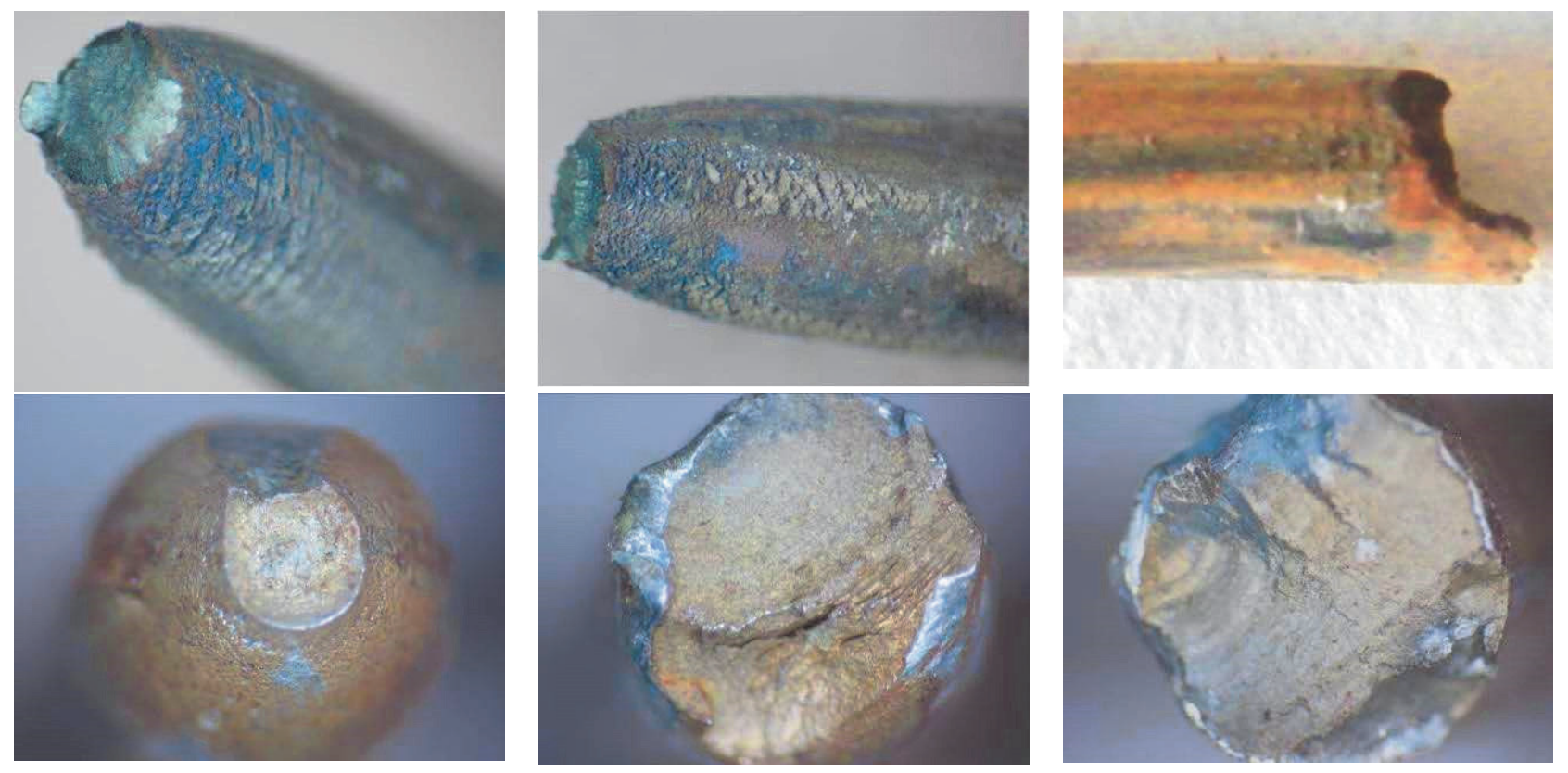

Figure 1 Examples of the fracture surface of core wire exposed 50 years

Newly produced galvanized wires used as conductors' strand core are tested for mechanical properties, but in last years the number of failed specimens increased so the analysis of reason had been performed. 
Factors affecting the physical properties of steel are:

- $\quad$ carbon content - carbon increased strength but decreased ductility,

- $\quad$ presence of impurities - inclusion type, shape, and orientation can be more important factors than total content [1,2],

- $\quad$ heat treatment processes - varies depending upon the type of treatment.

In general, in case study failure analyses, the actual fracture surfaces are available for metallographic analysis and evaluation, thus, the mode and mechanism of fracture are relatively easy to identify. A variety of loading and materials conditions can lead to fracture of wire with typical appearance of fracture surface appearance Figure 2.
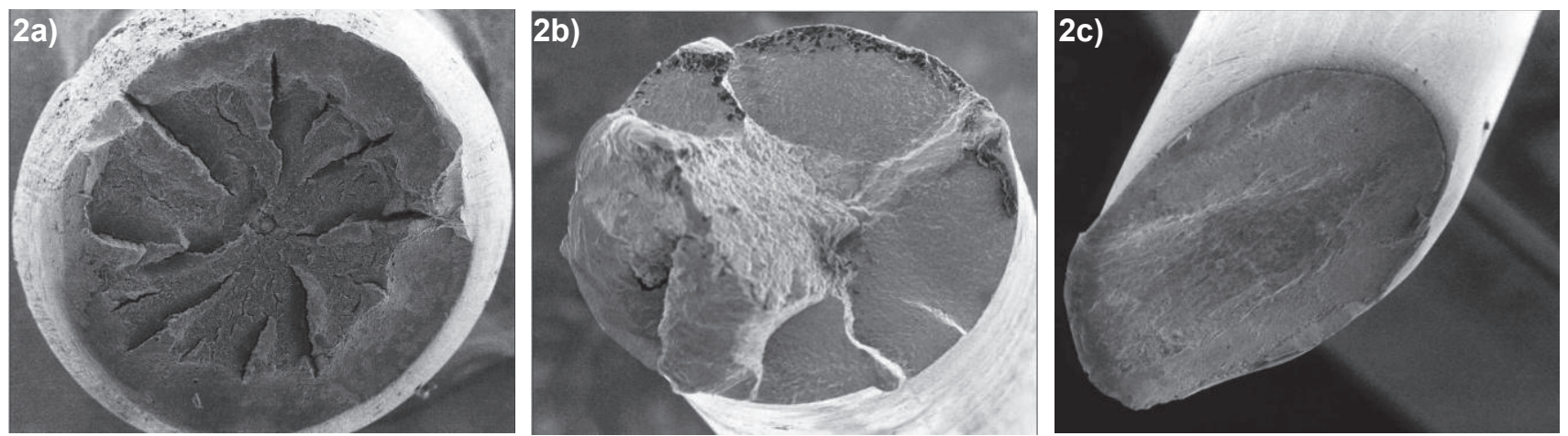

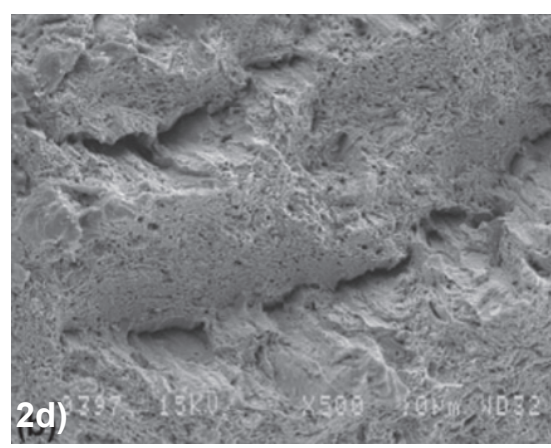

steel wire after tensile test - ductile fracture $(2 \mathrm{a}, 2 \mathrm{~d})$

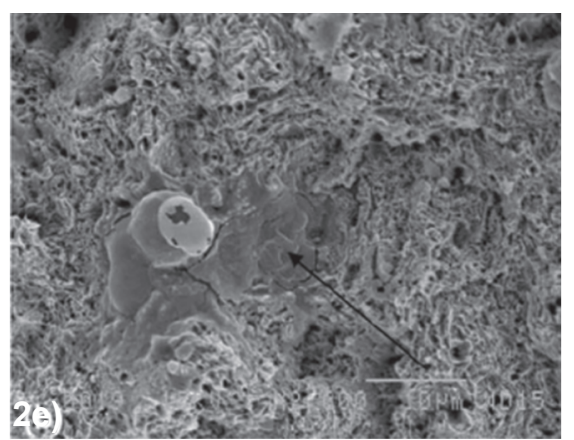

steel wire after round bending test ductile-brittle fracture $(2 b, 2 e)$

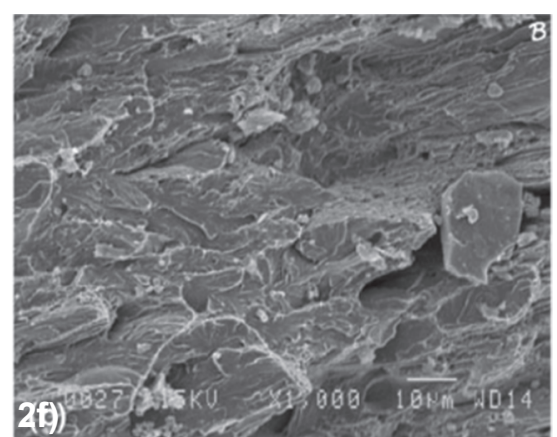

steel wire after twist test - ductilebrittle fracture $(2 \mathrm{c}, 2 \mathrm{f})$

Figure 2 Typical examples of the fracture surface appearance [3]

Brittle fracture, which was not observed, is identified by observing the typical features on the fractured surface; the origin of fracture is usually a matrix defect. A crack can also initiate in a defect-free material in a region of high stress concentration, such as at impurities amount in steel matrix. Brittle fracture surfaces have distinct characteristics:

- rapid crack propagation to fracture,

- the absence of gross plastic deformation,

- $\quad$ grained or faceted texture, along crystallographic (cleavage) planes,

- $\quad$ river marking or stress lines (chevron notches).

In steelmaking, impurities such as nitrogen, silicon, phosphorus, sulphur and excess carbon shall be removed from the sourced iron, but if they remained there, they may negatively affect the properties of steel products. Inclusions, including brittle oxides and more ductile manganese sulphides (MnS), affect fatigue endurance limit, fatigue crack propagation rate, fracture toughness, notch toughness, transverse tensile properties, and anisotropy of these properties with respect to the rolling direction. The increased use of scrap material as a 
source of iron has caused a sharp rise in impurities in steel. Most impurities in steel are metallic and can be classified in three categories: primary alloying, secondary alloying, and tramp elements.

The following are impurities commonly found in steel and the impact these have on quality, mainly mechanical properties: silicon (slightly raises the strength and hardness of steel), sulphur (forms iron sulphide which is a very brittle substance), phosphorous (increases the hardness and tensile strength of steel), nitrogen (sometimes a hardening and embrittling effect), etc.

\section{EXPERIMENTAL}

Conductor core 362AL1/59ST1A is made from 7 zinc coated steel strands with diameter $3.8 \mathrm{~mm}$ according to EN 50189 Conductors for overhead lines. Zinc coated steel wires. Substrate material is wire rod - Table 1.

Table 1 Chemical composition of steel for wires (wt\%)

\begin{tabular}{|c|c|c|c|c|c|c|c|}
\hline $\mathbf{C}$ & $\mathbf{M n}$ & $\mathbf{S i}$ & $\mathbf{P}$ & $\mathbf{S}$ & $\mathbf{C r}$ & $\mathbf{C u}$ & $\mathbf{N i}$ \\
\hline $0.13-0.20$ & $0.60-0.90$ & $0.15-0.40$ & 0.040 & 0.040 & $\max .0 .25$ & $\max .0 .30$ & $\max .0 .30$ \\
\hline
\end{tabular}

Before twisting the steel strand is tested in tensile strength, twist and winding. These tests are performed as standard for many years, but during last years of galvanized wire the most of productions failed in winding test - Figure 3. As there is not seen any deformation of plastic deformation of fracture surface it can be brittle fracture mode. The fracture surfaces of failed wires were examined by 3D optical microscope Keyence VHX5000 and electronic scanning microscope Tescan VEGA II - Figure 4 with energy dispersion analysis of elements EDAX by detector X-Max 50 SDD, fy Oxford Instruments. There were tested various failed wires from different production batches:

- $\quad$ specimen 1, new, failed - Figure $4 a$ - dark spots on fracture surface,

- $\quad$ specimen 2, new, failed - Figure 4b - typical "woody" brittle fracture appearance,

- $\quad$ specimen 3, 60 years exposed, passed in winding test.
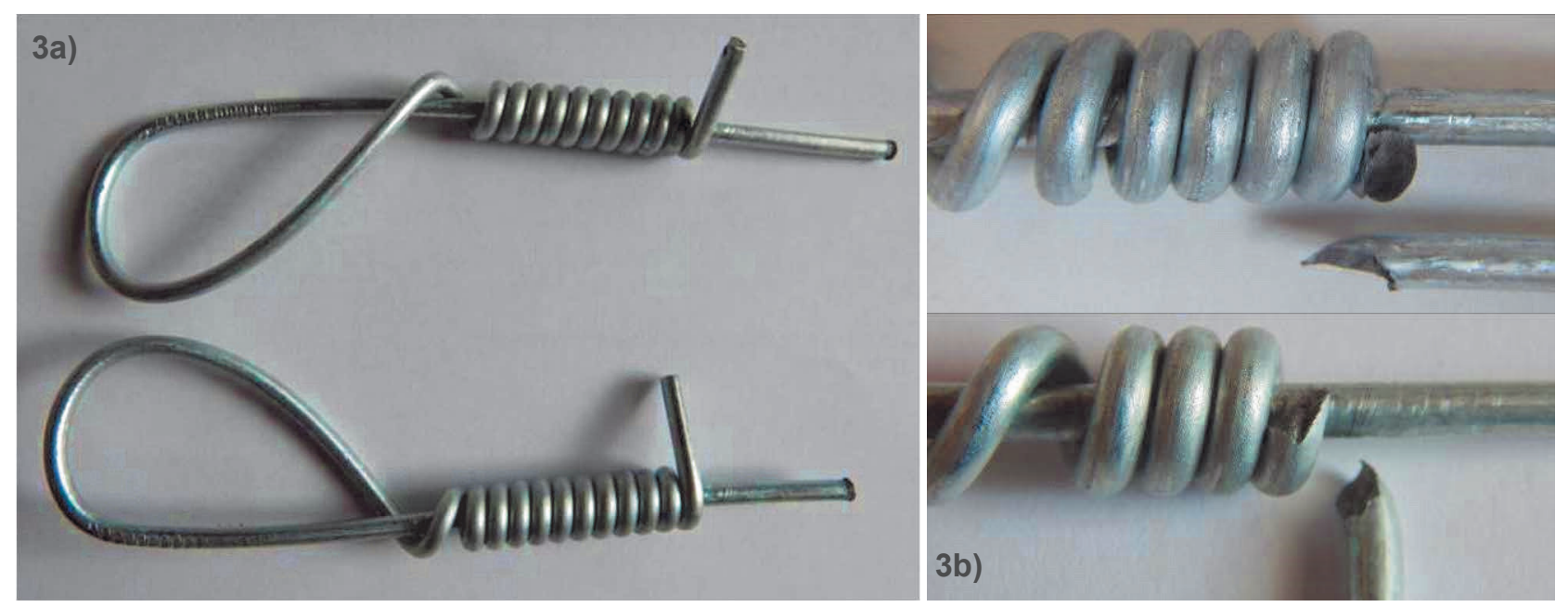

Figure 3 The winding test - passed (3a) and failed (3b) wire specimens

The different areas on the fracture surface were chosen to analyses with SEM equipped with EDAX. The results from specimen 1 are given on Figure 5 and average values on specific areas are given in Table 2. The high carbon content of the spot results in higher hardness of the steel wire. Other extremely high content was found for nitrogen which also increased the brittleness of steel. 

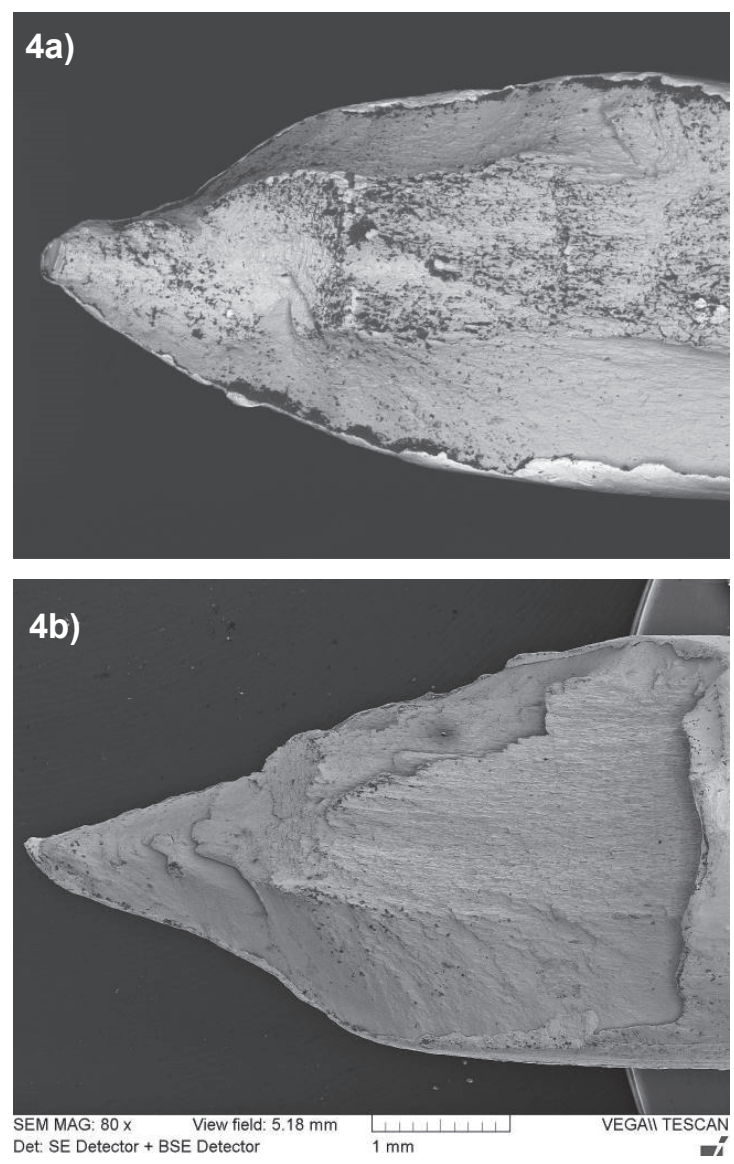
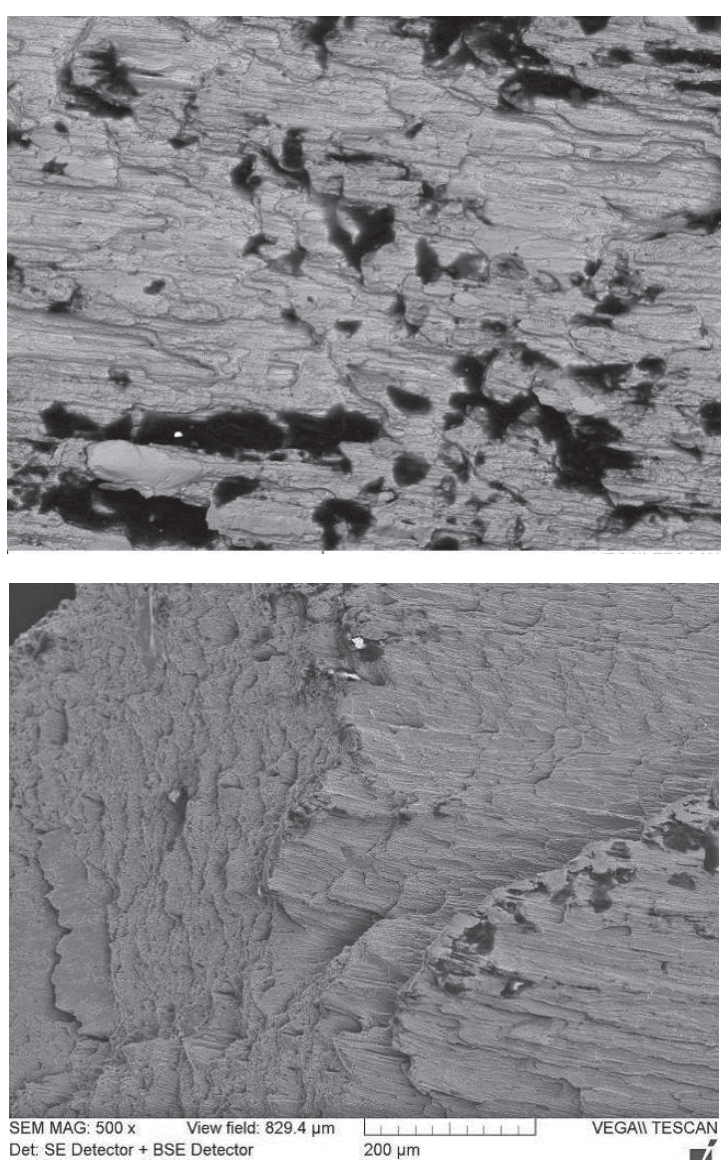

Figure 4 BSE scan of fracture surface - specimen 1 (4a) general view and detail, and specimen 2 (4b) general view and detail

Table 2 Elementary analysis of fracture surface of specimen 1 (Figure 4a) - selected elements (wt\%)

\begin{tabular}{|c|c|c|c|c|c|c|c|c|}
\hline Analysed area & $\mathbf{C}$ & $\mathbf{N}$ & $\mathbf{O}$ & $\mathbf{A l}$ & $\mathbf{S i}$ & $\mathbf{S}$ & $\mathbf{M n}$ & $\mathbf{F e}$ \\
\hline $5 \mathrm{a}$ & 61.6 & 9.8 & 19.5 & 0.09 & 0.11 & 0.63 & 0.17 & 4.6 \\
\hline $5 \mathrm{~b}$ & 56.9 & 9.6 & 12.4 & 0.35 & 0.68 & 1.59 & 0.20 & 10.7 \\
\hline reference area & 11.0 & 0.3 & 2.1 & 0.16 & 0.21 & 0.48 & 0.63 & 77.5 \\
\hline
\end{tabular}

On specimen 2 the different chemical composition of fracture surface was found - no nitrogen, relatively typical carbon content, so the other evaluation was performed to investigate the steel matrix structure by metallography. The specimens were withdrawn from wires along and across to fracture surfaces. For metallography, specimens were mechanically polished and etched. There had been seen in principle two different types of impurities according to morphology and chemical composition - Figure 6 and Table 3 . The chemical composition of steel matrix of specimen 3 is given in Table 4 and structure of steel matrix in both directions - longitudinal and transverse - on Figure 7.

Table 3 Elementary analysis of matrix of specimen 2 - selected elements (wt\%)

\begin{tabular}{|c|c|c|c|c|c|c|c|c|}
\hline Analysed area & $\mathbf{C}$ & $\mathbf{O}$ & $\mathbf{M g}$ & $\mathbf{A l}$ & $\mathbf{S i}$ & $\mathbf{S}$ & $\mathbf{C a}$ & $\mathbf{M n}$ \\
\hline $6 \mathrm{a}$ & 7.12 & 14.30 & 0.70 & 4.22 & 6.24 & 0.07 & 3.12 & 1.43 \\
\hline $6 \mathrm{~b}$ & 10.58 & 0.54 & - & - & 0.23 & 6.18 & - & 10.46 \\
\hline
\end{tabular}



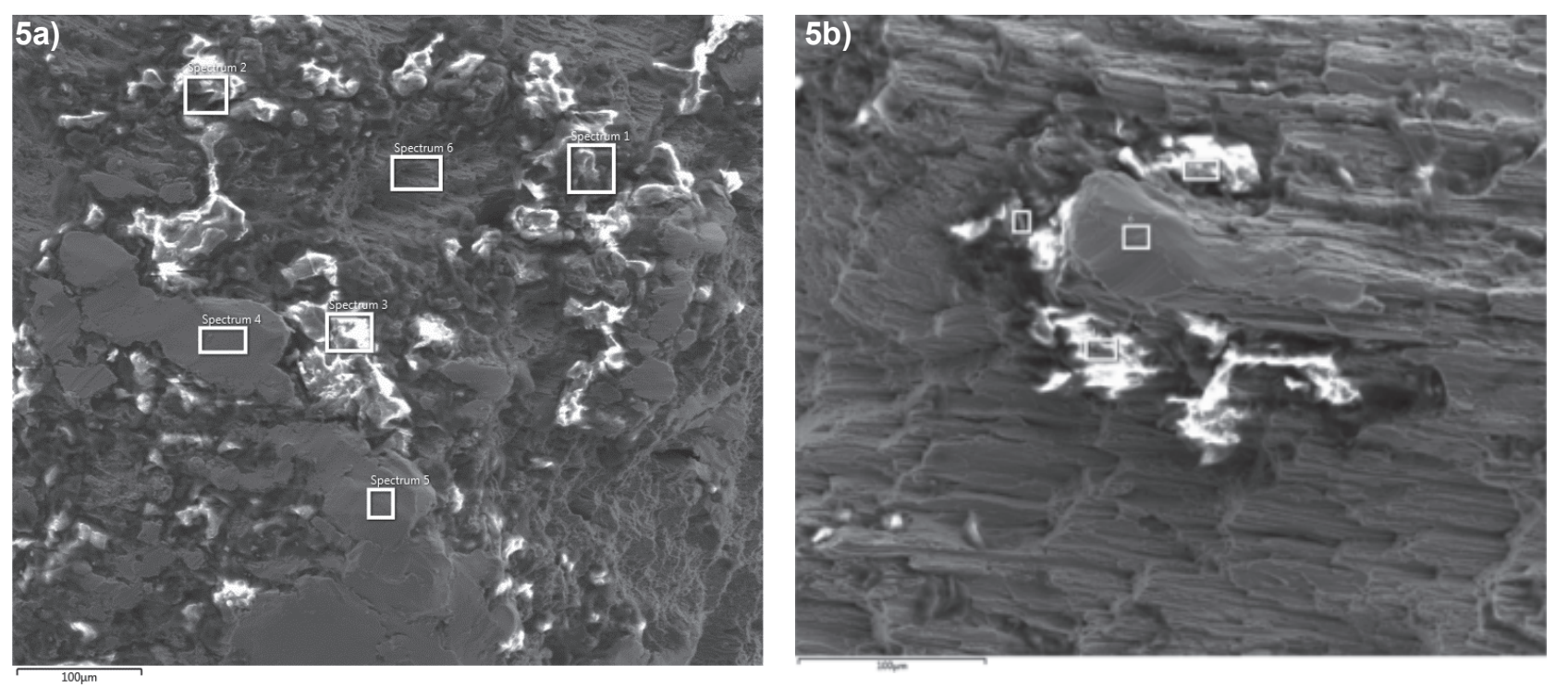

Figure 5 Analysed surfaces of specimen 1 (Figure 4a)
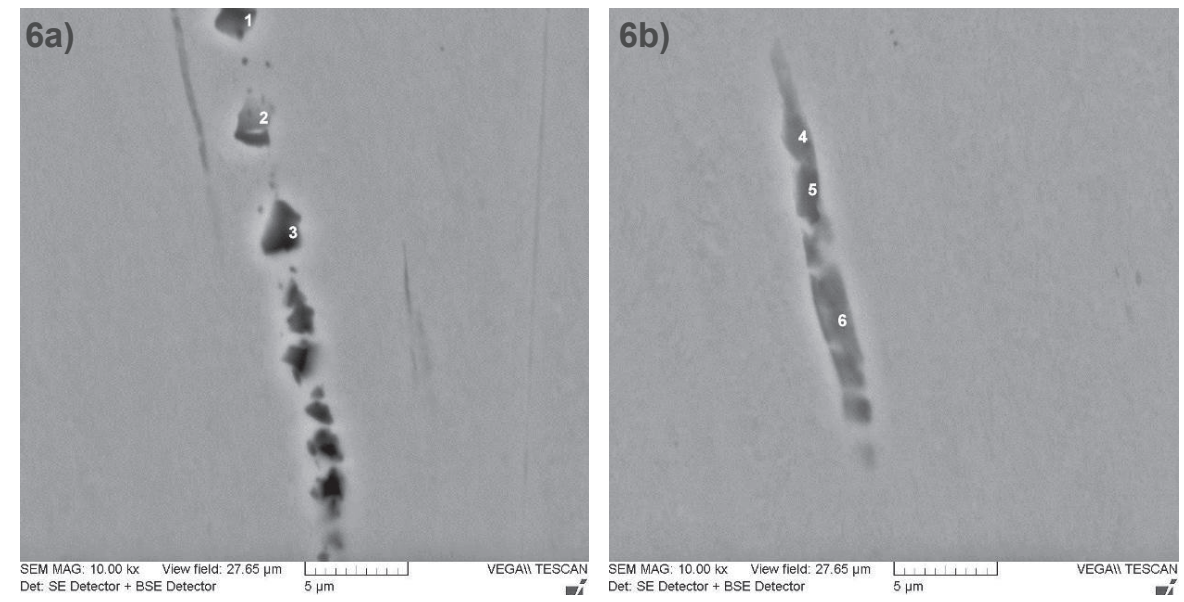

Figure 6 Metallography of cross section of specimen 2 (Figure $4 b$ ) with impurities
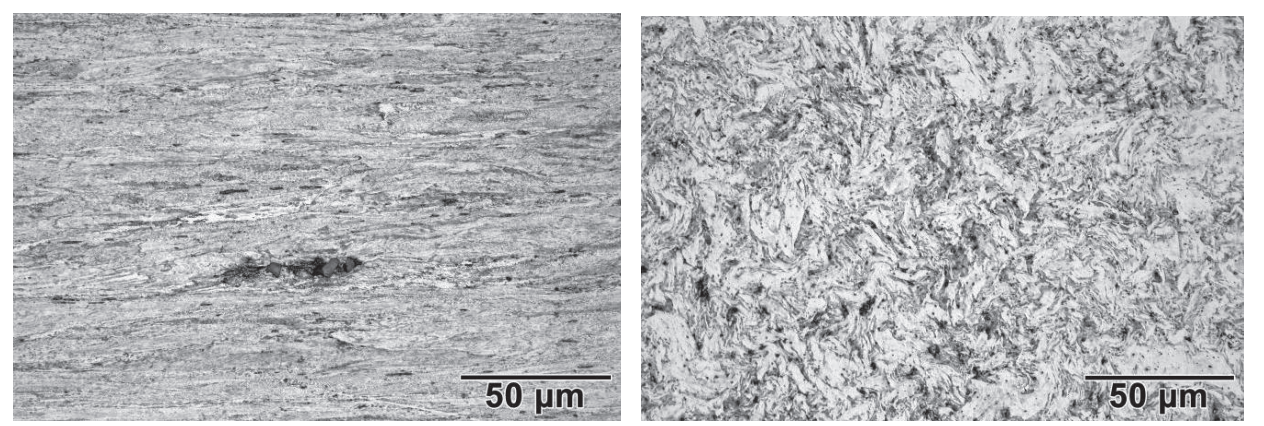

Figure 7 Metallography of cross section of specimen 3

Table 4 Elementary analysis of matrix of specimen $3(w t \%)$

\begin{tabular}{|c|c|c|c|c|c|c|c|}
\hline analysed area & $\mathbf{C}$ & $\mathbf{A l}$ & $\mathbf{S i}$ & $\mathbf{S}$ & $\mathbf{C r}$ & $\mathbf{M n}$ & $\mathbf{F e}$ \\
\hline matrix & 0.02 & 0.04 & 0.26 & 0.04 & 0.09 & 0.51 & 99.03 \\
\hline
\end{tabular}




\section{DISCUSSION}

Steel is alloyed with various elements to improve physical properties and to produce special properties such as resistance to corrosion or heat. The inclusions in carbon steel have the significant effects of on their mechanical properties. There is therefore clearly the need to identify and to quantify the effects of residual elements in order to keep these effects within acceptable limits. Impurities in steel can be classified under three different categories: primary alloying, secondary alloying, and tramp elements. The performed evaluation and analysis show various impurities in steel matrix resulting into increased strength, hardness and brittles of wires but the type of impurities differs in production periods:

- $\quad$ the specimen 1

- $\quad$ C - ductility, plasticity, forgeability and machinability decrease if the amount of carbon increases over 0,8 wt\%;

- $\quad \mathrm{N}$ - substitutes $\mathrm{C}$ in small amounts $(0.018 \mathrm{wt} \%)$ to increase hardness, brittleness and reduce plasticity; fractures occurred along the grain boundaries;

- $\quad$ the specimen 2

- $\quad \mathrm{Si}$ - increases tensile strength due to the formation of silicate inclusions, but it reduces the material's machinability;

- $\quad$ Al - increases toughness, especially at low temperatures;

- $\quad S$ - is responsible for reducing the impact strength, ductility in the transverse direction, and weldability in amount 0.05 wt $\%$;

- $\quad \mathrm{Mn}$ - increases hardenability, toughness, and tensile strength, but it hinders ductility through the formation of MnS precipitates; when too high carbon and too high manganese accompany each other, embrittlement sets in.

\section{CONCLUSION}

Non-metallic inclusions are one of the factors that influence the properties in particular fatigue strength of steel. The fatigue strength, represented by fatigue strength during rotary bending, is correlated with the size proportions and distances between the impurities measuring larger than $2 \mu \mathrm{m}$. The fracture morphology of broken winding specimens was carried out using optical and scanning electron microscopy with elementary analysis to establish fracture modes and reasons. Results indicate that winding testing is a better evaluator of the susceptibility of wire to brittle fracture than tensile tests and may also indicate the low chemical quality of steel. This type of combined conductors is in service for longer than 50 years and even the aluminium strands are failed, the steel core strands are strong enough to keep tensile strength of conductor - Figure 1.

\section{ACKNOWLEDGEMENTS}

\section{The study was performed and paper was written with support of project MPO - IP 8/2018.}

\section{REFERENCES}

[1] BELLOT, J. and GANTOIS, M. The influence of 'sulfide-type' inclusions on the mechanical properties of construction steels. Trans. Iron Steel Inst. Jpn. 1978. vol. 18, no. 9, pp. 546-553.

[2] THORNTON, P.A. The influence of nonmetallic inclusions on the mechanical properties of Steel: a review. J. Mater. Sci. 1971. vol. 6, pp. 347-356.

[3] KRISHNADEV, M., LAROUCHE, M., LAKSHMANAN, V. I. and SRIDHAR, R. Failure Analysis of Failed Wire Rope. J. Fail. Anal. and Preven.. 2010. vol. 10, no. 4, pp. 341-348. 